\title{
EDI committee at EGU: a success story of collaboration
}

DANIEL J. CONLEY ${ }^{1}$, CLAUDIA JESUS-RYDIN ${ }^{2}$ AND LISA WINGATE ${ }^{3}$

${ }^{1}$ Department of Geology, Lund University

${ }^{2}$ European Research Council (ERC)

${ }^{3}$ INRA, UMR ISPA

Presenting Author: daniel.conley@geol.lu.se

In 2016 a small group of people decided to convene a session at EGU dedicated to promoting and supporting equality in geosciences. No one had any direct contacts with the EGU structures or officers. It was moved by a genuine belief (maybe alongside with some naiveté) that we all can and must contribute to positive changes.

The session, in the format of an open call for abstracts, provided an opportunity to assess the interest of the EGU community in equality, diversity and inclusion (EDI) issues. The reaction from the community was overwhelming, including an unconditional support from more experienced colleagues based in the US and partner organisations including EAG. The session was a success and has been organised yearly ever-since.

Building on this experience and the group of engaged people leading it, in 2018 EGU Council decided on the creation of an EDI working group. Less than three years later, the EDI group was upgraded into a committee and has delivered numerous actions. These range from organisation of great debates, collaborative links to partner organisations, unconscious bias training to EGU officers, EGU data analysis, an EDI logo to EGU sessions, and many more initiatives in the pipeline.

In this talk we will share further details of this adventure: a success story of opening communication channels, creating trust and building bridges. 